\title{
Resistência Quantitativa à Ferrugem da Folha em Genótipos de Aveia Branca: II - Avaliação de Componentes de Resistência*
}

\author{
Márcia S. Chaves ${ }^{1}$, José A. Martinelli ${ }^{2}$ \& Luiz C. Federizzi ${ }^{3}$ \\ 1Embrapa Trigo, Cx. Postal 451, CEP 99001-970, Passo Fundo, RS, e-mail: mchaves@cnpt.embrapa.br; ${ }^{2}$ Departamento de \\ Fitossanidade; ${ }^{3}$ Departamento de Plantas de Lavoura, Faculdade de Agronomia, Universidade Federal do \\ Rio Grande do Sul, Cx. Postal 776, CEP 91540-000, Porto Alegre, RS
}

(Aceito para publicação em 26/09/2003)

Autor para correspondência: Márcia Soares Chaves

CHAVES, M.S., MARTINELLI, J.A. \& FEDERIZZI, L.C. Resistência quantitativa à ferrugem da folha em genótipos de aveia branca: II - Avaliação de componentes de resistência. Fitopatologia Brasileira 29:047-055. 2004.

\section{RESUMO}

A utilização da resistência quantitativa como forma de controle da ferrugem da folha da aveia (Avena sativa) pode ser uma alternativa viável, visto que há reação diferenciada entre genótipos em condições de campo, a qual apresenta grande espectro de variação. O progresso lento da moléstia observado a campo é o resultado dos efeitos combinados de componentes de resistência como baixa eficiência de infecção, período de latência longo, baixa produção de esporos por pústula e pequeno tamanho de pústulas. Este trabalho foi realizado durante os anos de 1999 e 2000, e teve por objetivo quantificar os componentes de resistência acima citados em 31 genótipos de aveia branca. A reação destes genótipos foi avaliada a campo, durante os anos de 1996 a 2000, os quais foram classificados em quatro grupos. A avaliação dos componentes de resistência foi realizada em plântulas e plantas adultas mantidas em condições controladas, sendo que os dois últimos componentes também foram quantificados em folhas coletadas nos ensaios de campo. Os genótipos apresentaram variabilidade para todas as características avaliadas, exceto para o período de latência em plântulas, sendo que aqueles classificados como resistentes no campo apresentaram a melhor combinação de componentes desejáveis.

Palavras-chave adicionais: Puccinia coronata f. sp. avenae, Avena sativa, seleção fenotípica, período de latência, eficiência de infecção.

\section{ABSTRACT}

Quantitative resistance to crown rust in white oat genotypes: II - Evaluation of resistance components

The use of quantitative resistance as a form to control oat (Avena sativa) crown rust can be a viable alternative, once there is differentiated reaction among oat genotypes in field, which shows great variation. The slow disease progress observed in the field is the result of combined effects of resistance components as low infection efficiency, longer latent period, low number of spores per pustule and little pustules size. This work was accomplished in 1999 and 2000, and its objective was to quantify the resistance

\section{INTRODUÇÃO}

A necessidade de formas de resistência mais eficientes para o controle da ferrugem da folha da aveia (Avena sativa L.) é uma realidade cada vez mais premente, uma vez que a tradicional resistência qualitativa não se tem mostrado durável, em função de vários fatores, relacionados ao patógeno e às condições do ambiente (Zimer et al., 1963; Federizzi \& Stuthman, 1998, Martinelli et al., 1998, Leonard, 1999). A resistência parcial ou quantitativa, a qual parece ser condicionada por genes de efeitos menores, pode ser uma alternativa de controle viável neste patossistema. Neste tipo de resistência, os genótipos

\footnotetext{
* Parte da Tese de Doutorado do primeiro autor. Universidade Federal do Rio Grande do Sul (2001).

${ }^{2,3}$ Bolsista do $\mathrm{CNPq}$
}

components above mentioned in 31 white oat genotypes. The reaction of these genotypes was evaluated in the field, from 1996 to 2000 , and they were classified in four groups. Evaluation of resistance components was accomplished in seedlings and adult plants maintained in controlled conditions, and the last two components were also quantified in leaves collected in the field trials. Genotypes showed variability for all measured characteristics, except for latent period in seedlings, and those genotypes classified as resistant in the field presented the best combination of desirable components. apresentam reações dentro de uma amplitude contínua de variação, podendo exibir desde nenhuma resistência (extrema suscetibilidade) até bons níveis de resistência (Parlevliet, 1989).

A resistência quantitativa é definida como um tipo de resistência incompleta, em que, embora o hospedeiro apresente reação de suscetibilidade, verifica-se uma baixa taxa de progresso da moléstia (Parlevliet, 1979; 1985). O progresso lento é o resultado dos efeitos combinados de componentes de resistência, tais como, baixa freqüência de infecção, período latente longo, pústulas pequenas, baixa produção de esporos por pústula e período infeccioso curto (Heagle \& Moore, 1970; Ohm \& Shaner, 1976; Sztejmberg \& Whal, 1976; Martin et al, 1979; Parlevliet, 1979; Whal et al, 1980). Em algumas interações patógeno-hospedeiro, um ou mais componentes podem ser responsáveis pela redução da moléstia 
no campo, o que se verifica, por exemplo, na interação cevada (Hordeum vulgare L.)-ferrugem da folha, com o aumento do período de latência (Parlevliet, 1976). O progresso lento da moléstia pode ser uma característica estável por períodos de tempo relativamente longos (Wilcoxson, 1981). Johnson (1984), após analisar diversas situações, concluiu que esta característica, embora não podendo ser considerada como um diagnóstico de resistência durável, é exibida por certas cultivares que têm mostrado resistência durável, sendo estas de grande valor para o estudo das causas da durabilidade.

Chaves et al. (2004), após cinco anos de avaliações de campo, verificou a ocorrência de resistência quantitativa à ferrugem da folha em genótipos de aveia branca desenvolvidos no sul do Brasil e adaptados a este ambiente, a qual se expressa em diferentes níveis. A investigação mais detalhada dos motivos que levam ao comportamento diferenciado destes genótipos no campo, envolve a quantificação dos componentes de resistência que contribuem para o progresso lento da moléstia. Neste sentido, o objetivo deste trabalho foi quantificar componentes de resistência à ferrugem da folha nos genótipos de aveia branca, cuja reação foi estudada nos ensaios de campo conduzidos por Chaves et al. (2004).

\section{MATERIALEMÉTODOS}

\section{Genótipos de aveia}

Este estudo foi realizado utilizando 31 genótipos de aveia branca (linhagens do Programa de Melhoramento Genético de Aveia da Faculdade de Agronomia da UFRGS e cultivares), cuja reação foi testada em condições de campo nos anos de 1996 a 2000 (Chaves et al., 2004).

\section{Inóculo}

Os esporos de ferrugem utilizados para as inoculações em sala climatizada e em casa de vegetação foram coletados na Estação Experimental Agronômica da UFRGS, em Eldorado do Sul, RS, nos anos de 1998 e 1999. A coleta foi realizada sobre folhas de diversos genótipos de aveia, com o auxílio de um aspirador de pó portátil, compondo uma mistura de raças do patógeno. Os esporos coletados foram levados para a Faculdade de Agronomia da UFRGS, onde foram armazenados sob vácuo em ampolas de vidro, sendo conservados em refrigerador $\left(4^{\circ} \mathrm{C}\right)$. As folhas de aveia coletadas nos ensaios de campo tiveram inoculação natural.

\section{Componentes de resistência}

Os componentes de resistência avaliados foram eficiência de infecção, período de latência, produção de esporos por pústula e tamanho de pústulas. Estes dados foram acessados a partir de um conjunto de ensaios desenvolvidos em condições controladas (sala climatizada e casa de vegetação) com plântulas e plantas adultas, e de avaliações em folhas de aveia coletadas em plantas adultas nos ensaios de campo (Chaves et al. , 2004).

\section{Avaliações em sala climatizada}

Nestas avaliações, foram quantificados sobre a primeira folha de plântulas a eficiência de infecção, o período de latência, o comprimento das pústulas e a produção de esporos por pústula.

Os genótipos de aveia em estudo foram semeados em potes plásticos com capacidade para $150 \mathrm{ml}$ contendo solo peneirado e mantidos em sala com condições controladas de temperatura $\left(22 \pm 2{ }^{\circ} \mathrm{C}\right)$ e luminosidade $(12 \mathrm{~h}$ de luz), no Departamento de Fitossanidade da Faculdade de Agronomia da UFRGS. A inoculação foi feita quando a primeira folha estava completamente expandida, sendo o método ajustado de acordo com o componente a ser quantificado. Para determinação do período de latência, do comprimento de pústulas e da produção de esporos por pústula, procedeu-se à inoculação das plântulas aspergindo-se uma suspensão de esporos, em água contendo uma gota de Tween 20 , com $10^{4}$ a $10^{5}$ esporos $/ \mathrm{ml}$. Nos ensaios que visavam determinar a eficiência de infecção, a inoculação foi feita de acordo com a metodologia descrita por Martinelli (1990) para o oídio da cevada. Antes da inoculação, as folhas foram aspergidas com água, e após, foram mantidas em câmara úmida, no escuro, por $12 \mathrm{~h}$.

Estes ensaios tiveram delineamento experimental inteiramente ao acaso, sendo o número de repetições diferente para cada ensaio, de acordo com o componente de resistência determinado.

\section{Eficiência de infecção}

Os genótipos foram semeados em potes plásticos e, após a emergência, foram deixadas três plantas por pote. Antes da inoculação, foram colocadas junto aos potes placas de Petri contendo meio Ágar-Água, onde foi contado o número de esporos germinados depositados por $\mathrm{cm}^{2}$. Decorridos dez dias após a inoculação contou-se o número de pústulas estabelecidas por $\mathrm{cm}^{2}$, na superfície inoculada (adaxial). A eficiência de infecção foi dada pela razão entre as duas contagens, e, em termos práticos, significa o número de esporos necessários para formar uma pústula. Quanto maior este valor, menor a eficiência de infecção e vice versa. Também foi quantificado o número de pústulas estabelecidas na superfície não inoculada (abaxial).

\section{Período de latência}

Os genótipos foram semeados em copos plásticos (três copos/genótipo), e após a emergência foram deixadas cinco plantas por pote, sendo considerado como unidade experimental cada copo com cinco plantas. Foi observado, para cada planta, o número de dias decorrido desde a inoculação até o aparecimento das primeiras uredopústulas (LP1), indicado para a seleção em um grande número de genótipos por estar altamente correlacionado com o LP 50, que corresponde ao período de tempo decorrido desde a inoculação até o surgimento de 50\% das pústulas (Broers, 1997). Calculou-se, a seguir, a média do período de latência entre as plantas de cada copo.

\section{Comprimento de uredopústulas}

As folhas inoculadas de cada genótipo foram coletadas 15 dias após a inoculação e herborizadas em refrigerador (Castro 
Resistência quantitativa à ferrugem da folha em genótipos de aveia...

\& Couto, 1998). Para a medição do comprimento das uredopústulas, utilizou-se o microscópio estereoscópico Leica MZ12 com lente ocular graduada, sob aumento de 80 vezes. Foram medidas 70 pústulas em cada genótipo.

\section{Produção de esporos por pústula}

As folhas inoculadas foram coletadas 15 dias após a inoculação, e os esporos já produzidos até aquele momento foram retirados da superfície foliar com um chumaço de algodão. A seguir foram cortados segmentos das folhas contendo um número variável de pústulas, os quais foram colocados em placas de Petri com meio Ágar-Água contendo sal de Benzimidazole (100 ppm). Este material foi incubado em sala com condições controladas de temperatura $\left(22 \pm 2{ }^{\circ} \mathrm{C}\right)$ e luminosidade $(12 \mathrm{~h}$ de luz) por $48 \mathrm{~h}$, para esporulação. Decorrido este tempo, foram selecionados três segmentos de folhas de cada genótipo, sendo contado o número de pústulas presentes em cada um deles sob microscópio estereoscópico. A seguir, cada segmento foi transferido para um tubo de ensaio contendo $3 \mathrm{ml}$ de solução de água-lactofenol azul de algodão (10:1) com $1 \mu$ de Tween 20. Os tubos foram agitados em agitador orbital vortex por 5 min, para retirada completa dos esporos. Estimou-se o número de esporos utilizando-se uma Câmara de Neubauer, sendo calculado a seguir, o número de esporos presentes nos $3 \mathrm{ml} \mathrm{da}$ suspensão de cada tubo. O número de esporos por pústula foi determinado através da divisão do número de esporos nos $3 \mathrm{ml}$ de suspensão pelo número de pústulas do segmento de folha do qual os esporos foram retirados.

\section{Avaliações em casa de vegetação}

Nestes ensaios foram quantificados sobre as folhas bandeira e bandeira-1 de plantas adultas, o período de latência, o comprimento de pústulas e a produção de esporos por pústula.

Os genótipos em estudo foram semeados em sacos plásticos para mudas com capacidade para 51 , contendo solo peneirado. Estes foram mantidos em casa de vegetação, na Faculdade de Agronomia da UFRGS. Após a emergência, foram deixadas cinco plantas por saco. Foram realizadas duas adubações de cobertura com uréia $(1 \mathrm{~g} / \mathrm{saco})$ nos estádios de duas e cinco folhas. Quando as plantas apresentaram as panículas completamente expostas, antes da fase de antese, procedeu-se à inoculação, a qual foi realizada pelo método de aspersão, utilizando uma suspensão de esporos provenientes do campo, com $10^{4}$ a $10^{5}$ esporos $/ \mathrm{ml}$. As plantas foram deixadas durante a noite em câmara úmida.

Estes ensaios tiveram delineamento experimental inteiramente ao acaso, sendo o número de repetições diferente para cada ensaio, de acordo com o componente de resistência determinado. O número de repetições e o método de avaliação de cada componente foram os mesmos utilizados nos ensaios com plântulas, em sala climatizada.

\section{Avaliações em folhas de aveia coletadas a campo}

Nos anos de 1998 e 1999 foram feitas amostragens de folhas bandeira e bandeira-1 dos 31 genótipos de aveia branca nos ensaios de campo conduzidos por Chaves (2001). Estas folhas foram acondicionadas em sacos de papel e levadas para o laboratório, no Departamento de Fitossanidade da Faculdade de Agronomia da UFRGS. Com este material foram quantificados os componentes de resistência comprimento de uredopústulas e produção de esporos por pústulas utilizando a mesma metodologia relatada nos ensaios sob condições controladas (sala climatizada e casa de vegetação).

\section{Análise estatística}

Os dados foram submetidos à análise de variância (ANOVA), e a discriminação da variação entre os tratamentos foi feita pelo teste Tukey ao nível de 5\% de probabilidade. Utilizou-se o programa SANEST-Sistema de Análise Estatística para Microcomputadores (Zonta \& Machado, 1984).

\section{RESULTADOS}

\section{Avaliações em condições controladas Eficiência de infecção}

Verificaram-se diferenças significativas entre os genótipos testados $(\mathrm{P}>\mathrm{F}=0,00001)$, observando-se desde 32,2 até 2376,1 esporos necessários para formar uma pústula. Dentre os genótipos em que se observou alta eficiência de infecção (menores valores) estão as linhagens UFRGS 953167, UFRGS 911748-1, UFRGS 41721-21, UFRGS 94638-B e as testemunhas suscetíveis UFRGS 14 e UFRGS 7. A menor eficiência de infecção foi observada na linhagem UFRGS 960845-2, sendo que na cultivar CTC 3 e nas linhagens UFRGS 953304, UFRGS 953133, UFRGS 940263-3 também ocorreu baixa eficiência de infecção pelo patógeno (Tabela 1). Observou-se alta correlação positiva $(\mathrm{r}=0,97)$ entre o número de pústulas formadas na superfície inoculada (adaxial) e o número de pústulas formadas na superfície não inoculada (abaxial) (dados não mostrados).

\section{Período de latência}

Houve interação significativa entre os estádios avaliados e os 31 genótipos em estudo $(\mathrm{P}>\mathrm{F}=0,00001)$. Em plântulas, não houve diferença significativa entre os genótipos, observandose período de latência de 7,5 a oito dias. Em plantas adultas, os genótipos diferenciaram-se significativamente quanto à característica em questão, a qual variou de 9,2 a 14,4 dias (Tabela 2). O maior período de latência foi nas linhagens UFRGS 953133 e UFRGS 940263-3, sendo que as linhagens UFRGS 910906 e UFRGS 93641 também se destacaram dos demais genótipos pelo período de latência mais longo. Os genótipos com menor período de latência neste estádio foram as testemunhas UFRGS 7 e UFRGS 14, sendo que na linhagem UFRGS 940772 também houve um curto período de latência. Na comparação entre o período de latência de plântulas e de plantas adultas, em todos os genótipos houve diferença significativa entre os estádios, tendo sido mais longo em plantas adultas.

A interação significativa entre os estádios avaliados, plântula e planta adulta, e os 31 genótipos em estudo foi também verificada quando se procedeu à ANOVA do componentes de resistência comprimento de pústula e produção de esporos por pústula $(\mathrm{P}>\mathrm{F}=0,00001)$. 
M.S. Chaves et al.

TABELA 1 - Eficiência de infecção $\left(\mathrm{n}^{\circ}\right.$ de esporos necessários para formar uma pústula) da ferrugem da folha da aveia (Avena sativa) na primeira folha de plântulas em condições controladas (Faculdade de Agronomia/UFRGS, 2000). Dados referentes a médias de dois experimentos

\begin{tabular}{lrl}
\hline Genótipo & Eficiência de infecção \\
\hline UFRGS 960845-2 & $2376,1 \mathrm{a}$ \\
UFRGS 940263-3 & $975,3 \mathrm{~b}$ \\
UFRGS 953133 & $680,3 \mathrm{bc}$ \\
UFRGS 953304 & $372,1 \mathrm{~cd}$ \\
CTC 3 & $354,0 \mathrm{~d}$ \\
UFRGS 952403 & $282,4 \mathrm{de}$ \\
UFRGS 950120 & 241,8 def \\
UFRGS 42085-10 & 223,6 defg \\
UFRGS 17 & 215,6 defgh \\
UFRGS 10 & 169,8 defghi \\
UFRGS 922003 & 122,2 efghi \\
UFRGS 953285 & 117,8 efghi \\
UFRGS 41698-22 & 117,2 efghi \\
UFRGS 93576 & 111,8 efghi \\
UFRGS 921260 & 106,4 efghi \\
UFRGS 952602 & 104,5 efghi \\
UFRGS 93641 & 95,2 efghi \\
UFRGS 910906 & 91,3 efghi \\
UFRGS 16 & 85,6 fghi \\
UFRGS 41699-3 & 79,7 fghi \\
UFRGS 940772 & 77,5 fghi \\
UFRGS 14 & 73,7 fghi \\
UFRGS 953167 & 61,1 ghi \\
UFRGS 911748-1 & 54,5 hi \\
UFRGS 953109 & 50,3 i \\
UFRGS 41721-21 & 48,2 i \\
UFRGS 94638-B & 45,9 i \\
UFRGS 7 & 32,2 i \\
\hline C. V. (\%) & 2,30 & \\
\hline
\end{tabular}

Médias seguidas por letras distintas diferem entre si pelo teste de Tukey ao nível de $5 \%$ de probabilidade.

\section{Comprimento de uredopústulas}

O comprimento de pústulas no estádio de plântula variou de 261,1 a 381,4 $\mu \mathrm{m}$ (Tabela 3). As maiores pústulas foram observadas na linhagem UFRGS 41698-22, sendo que a linhagem UFRGS 953304 e a cultivar UFRGS 14 também tiveram pústulas grandes. As menores pústulas neste estádio foram nos genótipos UFRGS 953133 e UFRGS 960845-2, sendo que nas linhagens UFRGS 922003, UFRGS 953109 e UFRGS 953285 também se observaram pústulas pequenas. Em plantas adultas, o comprimento de pústulas variou de 270,6 a 354,9 $\mu \mathrm{m}$ (Tabela 3). Neste estádio, as maiores pústulas foram observadas na cultivar UFRGS 10, sendo que na cultivar UFRGS 17 e nas linhagens UFRGS 940772, UFRGS 950120 e UFRGS 953167 também se observaram pústulas grandes. Destacaram-se por pústulas pequenas em plantas adultas as linhagens UFRGS 952602, UFRGS 953133, UFRGS 952403, UFRGS 910906, UFRGS 41709-5 e UFRGS 960286-1, sendo UFRGS 960845-2 o genótipo com as menores pústulas. O comprimento de pústulas de plântulas e de plantas adultas foi significativamente diferente em todos os genótipos; com exceção da linhagem UFRGS 960845-2, na qual o comprimento de pústulas de plântulas e de plantas adultas foi igual. Dentre os trinta genótipos onde foi
TABELA 2 - Período de latência da ferrugem da folha em genótipos de aveia (Avena sativa), em plântulas (primeira folha) e em plantas adultas (folhas bandeira e bandeira-1) em condições controladas (Faculdade de Agronomia/UFRGS, 1999). Dados referentes a médias de dois experimentos

\begin{tabular}{|c|c|c|c|}
\hline \multirow{2}{*}{ Genótipo } & \multicolumn{3}{|c|}{ Período de latência (dias) } \\
\hline & Plântula & Plar & ta adulta \\
\hline UFRGS 953133 & 8,0 a $\mathrm{A}$ & 14,4 & a B \\
\hline UFRGS 940263-3 & 7,5 a $\mathrm{A}$ & 14,4 & a B \\
\hline UFRGS 910906 & 7,6 a $\mathrm{A}$ & 13,3 & $a b B$ \\
\hline UFRGS 93641 & 7,6 a $\mathrm{A}$ & 13,1 & abc B \\
\hline UFRGS 16 & 7,7 a $\mathrm{A}$ & 12,9 & abcd B \\
\hline UFRGS 92576 & 7,8 a $\mathrm{A}$ & 12,7 & abcde B \\
\hline UFRGS 911748-1 & 7,7 a $\mathrm{A}$ & 12,7 & abcde B \\
\hline UFRGS 953304 & 7,6 a $\mathrm{A}$ & 12,6 & abcdef B \\
\hline UFRGS 41709-5 & 7,8 a $\mathrm{A}$ & 12,5 & abcdefg B \\
\hline UFRGS 960845-2 & 7,8 a $\mathrm{A}$ & 12,5 & abcdefg B \\
\hline UFRGS 952403 & 7,6 a $\mathrm{A}$ & 12,4 & abcdefg B \\
\hline UFRGS 922003 & 7,6 a $\mathrm{A}$ & 12,3 & abcdefgh B \\
\hline CTC 3 & 7,7 a $\mathrm{A}$ & 12,2 & bcdefgh B \\
\hline UFRGS 41699-22 & 7,6 a $\mathrm{A}$ & 12,0 & bcdefghi $\mathrm{B}$ \\
\hline UFRGS 950120 & 7,6 a $\mathrm{A}$ & 11,9 & bcdefghi $\mathrm{B}$ \\
\hline UFRGS 960286 & 7,6 a $\mathrm{A}$ & 11,8 & bcdefghi $\mathrm{B}$ \\
\hline UFRGS 41721-21 & 7,6 a $\mathrm{A}$ & 11,3 & bcdefghi $\mathrm{B}$ \\
\hline UFRGS 94638 & 7,6 a $\mathrm{A}$ & 11,3 & bcdefghij $\mathrm{B}$ \\
\hline UFRGS 42085-10 & 7,8 a $\mathrm{A}$ & 11,2 & bcdefghij $B$ \\
\hline UFRGS 953285 & 7,7 a $\mathrm{A}$ & 11,2 & bcdefghij $\mathrm{B}$ \\
\hline UFRGS 952602 & 7,6 a $\mathrm{A}$ & 11,1 & cdefghij B \\
\hline UFRGS 17 & 7,6 a $\mathrm{A}$ & 11,0 & cdefghij B \\
\hline UFRGS 953167 & 7,7 a $\mathrm{A}$ & 10,9 & defghij B \\
\hline UFRGS 10 & 7,6 a $\mathrm{A}$ & 10,6 & efghij B \\
\hline UFRGS 953109 & 7,6 a $\mathrm{A}$ & 10,5 & fghij B \\
\hline UFRGS 41699-3 & 7,8 a $\mathrm{A}$ & 10,4 & ghij B \\
\hline UFRGS 952576-1 & 7,5 a $\mathrm{A}$ & 10,4 & ghij $B$ \\
\hline UFRGS 921260 & 7,8 a $\mathrm{A}$ & 10,2 & hij B \\
\hline UFRGS 940772 & 7,6 a $\mathrm{A}$ & 10,0 & ij $B$ \\
\hline UFRGS 14 & 7,7 a $\mathrm{A}$ & 9,5 & j B \\
\hline UFRGS 7 & 7,6 a $\mathrm{A}$ & 9,2 & $\mathrm{j} B$ \\
\hline C. V. $(\%)$ & & & \\
\hline
\end{tabular}

Médias seguidas por letras distintas diferem entre si pelo teste de Tukey ao nível de $5 \%$ de probabilidade.

Letras maiúsculas indicam comparação entre estádios.

Letras minúsculas indicam comparações entre genótipos

verificada diferença significativa entre os estádios, a cultivar UFRGS 10 e as linhagens UFRGS 953167, UFRGS 953109, UFRGS 940772, UFRGS 953133, UFRGS 922003 e UFRGS 950120 tiveram pústulas maiores em plantas adultas, sendo que nas demais, as maiores pústulas foram observadas no estádio de plântula.

\section{Produção de esporos por pústula}

O número de esporos por pústula no estádio de plântula, variou de 613,3 a 1477,8 , tendo sido observada maior esporulação na linhagem UFRGS 92576 (Tabela 4). Destacaramse também, por alta esporulação, as cultivares UFRGS 10 e UFRGS 7 e as linhagens UFRGS 922003, UFRGS 41721-21 e UFRGS 41698-22. O genótipo UFRGS 960845-2 teve a menor produção de esporos por pústula neste estádio, sendo que nas linhagens UFRGS 953167 e UFRGS 910906 a esporulação também foi baixa. Em plantas adultas, observou-se entre os 
Resistência quantitativa à ferrugem da folha em genótipos de aveia...

TABELA 3 - Comprimento de pústulas da ferrugem da folha em genótipos de aveia (Avena sativa), em plântulas (primeira folha) e em plantas adultas (folhas bandeira e bandeira-1) em condições controladas (Faculdade de Agronomia/UFRGS, 1999/2000 - dados referentes a médias de dois experimentos), e em condições de campo (EEA/UFRGS, 1998/1999)

\begin{tabular}{|c|c|c|c|c|c|c|c|c|}
\hline \multirow{4}{*}{$\begin{array}{l}\text { Genótipo } \\
\text { UFRGS 41698-22 }\end{array}$} & \multicolumn{8}{|c|}{ Comprimento de pústulas $(\mu \mathrm{m})$} \\
\hline & \multicolumn{4}{|c|}{ Condições controladas } & \multicolumn{4}{|c|}{ Campo } \\
\hline & \multicolumn{2}{|c|}{ Plântula } & \multicolumn{2}{|c|}{ Planta adulta } & \multicolumn{2}{|c|}{1998} & \multicolumn{2}{|c|}{1999} \\
\hline & 381,4 & a A & 300,1 & fg $B$ & 620,2 & $a b c$ & 510,0 & $\mathrm{~b}$ \\
\hline UFRGS 953304 & 343,8 & b A & 290,5 & hij B & 537,8 & jklm & 403,8 & jklm \\
\hline UFRGS 14 & 341,3 & bc A & 299,9 & fg B & 567,8 & fghij & 545,5 & a \\
\hline UFRGS 42085-10 & 338,8 & bcd A & 288,8 & hij $B$ & 552,3 & hijk & 487,6 & $\mathrm{bc}$ \\
\hline UFRGS 17 & 335,4 & bcde A & 321,0 & c B & 522,4 & $\mathrm{klm}$ & 467,6 & $\mathrm{~cd}$ \\
\hline UFRGS 10 & 333,2 & bcde B & 354,9 & a A & 553,5 & hijk & 419,5 & hijk \\
\hline UFRGS 41709-5 & 332,5 & bcde A & 277,9 & $\mathrm{kl} \quad \mathrm{B}$ & 501,6 & $\mathrm{~m}$ & 428,0 & fghij \\
\hline CTC 3 & 331,7 & bcde A & 308,3 & ef $B$ & 591,4 & cdefg & 454,8 & def \\
\hline UFRGS 16 & 331,7 & bcde A & 287,4 & ij $\quad B$ & 636,0 & $\mathrm{ab}$ & 449,1 & defg \\
\hline UFRGS 940772 & 330,5 & bcde B & 347,5 & $\mathrm{ab} A$ & 612,5 & abcde & 383,6 & $\mathrm{mn}$ \\
\hline UFRGS 7 & 330,0 & cde A & 311,7 & de B & 601,4 & bcdef & 412,5 & hijkl \\
\hline UFRGS 910906 & 326,9 & def $A$ & 281,9 & $\mathrm{jk} \quad \mathrm{B}$ & 521,4 & klm & 398,0 & klm \\
\hline UFRGS 911748-1 & 325,0 & efg A & 306,9 & ef $B$ & 521,0 & klm & 424,1 & ghijk \\
\hline UFRGS 940263-3 & 323,7 & efg $A$ & 288,5 & hij B & 564,5 & fghij & 391,2 & $\operatorname{lmn}$ \\
\hline UFRGS 952403 & 323,5 & efg A & 282,4 & $\mathrm{jk} \quad \mathrm{B}$ & 598,4 & cdef & 459,1 & de \\
\hline UFRGS 952576-1 & 323,5 & efg $A$ & 319,0 & cd B & 553,7 & hijk & 426,2 & ghij \\
\hline UFRGS 41721-21 & 323,2 & efg $A$ & 301,2 & fg B & 572,7 & fghij & 405,7 & ijklm \\
\hline UFRGS 921260 & 322,5 & efg $\mathrm{A}$ & 308,6 & ef $B$ & 522,5 & $\mathrm{klm}$ & 418,5 & hijk \\
\hline UFRGS 94638-B & 322,4 & efg $A$ & 294,0 & ghi B & 544,0 & ijkl & 431,4 & fghi \\
\hline UFRGS 952602 & 322,0 & efg $A$ & 283,7 & $\mathrm{jk} \quad \mathrm{B}$ & 519,3 & $\mathrm{klm}$ & 434,2 & efgh \\
\hline UFRGS 953167 & 315,2 & fgh B & 327,2 & c A & 587,5 & cdefgh & 412,8 & hijkl \\
\hline UFRGS 950120 & 315,1 & fgh $B$ & 339,9 & b A & 561,3 & ghij & 468,7 & $\mathrm{~cd}$ \\
\hline UFRGS 41699-3 & 312,8 & ghi A & 296,0 & ghi B & 616,7 & abcd & 409,1 & hijklm \\
\hline UFRGS 92576 & 312,7 & ghi A & 289,8 & hij B & 553,7 & hijk & 406,2 & ijklm \\
\hline UFRGS 93641 & 305,6 & hij A & 296,5 & gh B & 520,7 & klm & 368,8 & $\mathrm{n}$ \\
\hline UFRGS 960286-1 & 302,7 & hij A & 277,2 & $\mathrm{kl} \quad \mathrm{B}$ & 578,7 & efghi & 409,2 & hijklm \\
\hline UFRGS 953285 & 300,8 & ij A & 293,1 & ghi B & 612,1 & abcde & 419,4 & hijk \\
\hline UFRGS 953109 & 297,1 & j $B$ & 307,5 & ef $\mathrm{A}$ & 575,7 & efghi & 447,7 & defg \\
\hline UFRGS 922003 & 286,2 & $\mathrm{k} \mathrm{A}$ & 293,8 & ghi B & 515,1 & $\operatorname{lm}$ & 409,8 & hijklm \\
\hline UFRGS 960845-2 & 270,6 & $1 \mathrm{~A}$ & 270,6 & $1 \mathrm{~A}$ & 582,1 & defgh & $*$ & \\
\hline UFRGS 953133 & 261,1 & $1 \mathrm{~B}$ & 283,1 & $\mathrm{jk} \quad \mathrm{A}$ & 639,8 & $\mathrm{a}$ & 417,1 & hijkl \\
\hline C. V. (\%) & & & 83 & & & 9,31 & & 14 \\
\hline
\end{tabular}

Médias seguidas por letras distintas diferem entre si pelo teste de Tukey ao nível de 5\% de probabilidade.

Letras maiúsculas indicam comparação entre estádios.

Letras minúsculas indicam comparação entre genótipos.

* O genótipo não apresentou pústulas em número suficiente para a avaliação.

genótipos uma variação de 315,2 a 1037,8 esporos por pústula (Tabela 4). Neste estádio, verificou-se maior esporulação na linhagem UFRGS 940772, sendo que na cultivar UFRGS 17 e nas linhagens UFRGS 91178-1 e UFRGS 41698-22 a esporulação também foi alta. Os genótipos UFRGS 910906, UFRGS 922003, UFRGS 960845-2 e UFRGS 953285 destacaram-se por baixa produção de esporos por pústula. Houve diferença significativa entre a esporulação em plântulas e em plantas adultas nas cultivares UFRGS 7, UFRGS 10 e UFRGS 16, e nas linhagens UFRGS 952403, UFRGS 94638-B, UFRGS 41721-21, UFRGS 953133, UFRGS 953304, UFRGS 953285, UFRGS $940263-$ 3,UFRGS910906,UFRGS 922003, UFRGS 92576eUFRGS 921260. Em todos estes genótipos, a maior esporulação foi verificada no estádio de plântula.
Avaliações em folhas coletadas a campo

Comprimento de uredopústulas

Houve diferença significativa entre os genótipos quanto ao comprimento de pústulas de folhas bandeira e bandeira-1 provenientes do campo em ambos os anos, 1998 e 1999 $(\mathrm{P}>\mathrm{F}=0,00001)$.

Em 1998, o comprimento de pústulas variou de 501,6 a $639,8 \mu \mathrm{m}$ (Tabela 3). As maiores pústulas foram observadas no genótipo UFRGS 953133, sendo que UFRGS 16 e UFRGS 4169822 também apresentaram pústulas grandes. A cultivar UFRGS 17 e as linhagens UFRGS 921260, UFRGS 910906, UFRGS 911748, UFRGS 93641,UFRGS 952602, UFRGS 922003 eUFRGS 41709-5 destacaram-se por apresentar pústulas pequenas, sendo que a última foi a que apresentou as menores pústulas. 
M.S. Chaves et al.

TABELA 4 - Produção de esporos por pústula de ferrugem da folha em genótipos de aveia (Avena sativa), em plântulas (primeira folha) e em plantas adultas (folhas bandeira e bandeira-1) em condições controladas (Faculdade de Agronomia/ UFRGS, 1999/2000 - dados referentes a médias de dois experimentos), e em condições de campo (EEA/UFRGS, 1998/1999)

\begin{tabular}{|c|c|c|c|c|c|c|}
\hline \multirow{4}{*}{$\begin{array}{l}\text { Genótipo } \\
\text { UFRGS } 92576\end{array}$} & \multicolumn{6}{|c|}{ Número de esporos/pústula } \\
\hline & \multicolumn{3}{|c|}{ Condições controladas } & \multicolumn{3}{|c|}{ Campo } \\
\hline & Plântula & \multicolumn{2}{|c|}{ Planta adulta } & 1998 & \multicolumn{2}{|c|}{1999} \\
\hline & 1477,8 a $\mathrm{A}$ & 876,4 & abcd B & $355,3 \mathrm{~cd}$ & 1537,6 & bcde \\
\hline UFRGS 10 & 1351,8 ab A & 566,3 & abcde B & $*$ & 1702,6 & abcde \\
\hline UFRGS 922003 & 1241,7 abc A & 402,2 & de $B$ & $277,7 \mathrm{~cd}$ & 2276,1 & abcd \\
\hline UFRGS 41721-21 & 1240,7 abc A & 646,3 & abcde B & $332,4 \mathrm{~cd}$ & 1133,9 & de \\
\hline UFRGS 4169822 & 1231,1 abc $\mathrm{A}$ & 916,9 & abc A & $340,4 \mathrm{~cd}$ & 1314,8 & de \\
\hline UFRGS 7 & 1225,8 abc $\mathrm{A}$ & 669,6 & abcde B & $340,7 \mathrm{~cd}$ & 1406,8 & cde \\
\hline UFRGS 940263-3 & 1213,6 abcd $\mathrm{A}$ & 504,2 & abcde B & 446,5 abcd & 1559,0 & abcde \\
\hline UFRGS 94638-B & 1154,6 abcd $\mathrm{A}$ & 524,2 & abcde B & 406,3 bcd & 1049,3 & de \\
\hline UFRGS 911748 -1 & 1138,4 abcd A & 920,3 & $\mathrm{abc} A$ & $354,9 \mathrm{~cd}$ & 1441,5 & bcde \\
\hline UFRGS 953133 & 1135,8 abcd A & 651,0 & abcde B & $283,4 \mathrm{~cd}$ & 1119,3 & de \\
\hline UFRGS 952403 & 1123,0 abcd A & 789,2 & abcd B & $*$ & 959,7 & $\mathrm{e}$ \\
\hline UFRGS 950120 & 1102,4 abcd A & 850,5 & abcd A & 734,7 abc & 1181,9 & de \\
\hline UFRGS 953285 & 1097,8 abcd $\mathrm{A}$ & 458,3 & cde B & 501,4 abcd & 1073,7 & de \\
\hline UFRGS 42085-10 & 1086,3 abcd A & 804,8 & abcd A & 399,4 bcd & 1145,2 & de \\
\hline UFRGS 41709-5 & 1072,1 abcd A & 839,3 & abcd A & 515,7 abcd & 2694,3 & $a b$ \\
\hline UFRGS 953109 & 1026,4 abcd A & 721,2 & abcde A & 512,3 abcd & 932,5 & e \\
\hline UFRGS 921260 & 1001,5 abcd $\mathrm{A}$ & 520,8 & abcde B & $160,4 \mathrm{~d}$ & 1112,7 & de \\
\hline UFRGS 952576-1 & 971,3 abcd $A$ & 773,1 & abcde A & 420,9 abcd & 980,1 & $\mathrm{e}$ \\
\hline UFRGS 953304 & 966,2 abcd $A$ & 637,7 & abcde B & $362,3 \mathrm{~cd}$ & 1324,0 & de \\
\hline UFRGS 960286-1 & 951,8 abcd $\mathrm{A}$ & 688,9 & abcde A & 526,7 abcd & 908,0 & $\mathrm{e}$ \\
\hline UFRGS 41699-3 & 938,2 abcd $\mathrm{A}$ & 570,9 & abcde B & $871,2 \mathrm{ab}$ & $\mathrm{E} 7,0$ & abcde \\
\hline UFRGS 16 & 933,3 abcd $\mathrm{A}$ & 581,0 & abcde B & 906,7 a & 2654,6 & $a b c$ \\
\hline CTC 3 & 924,0 abcd $\mathrm{A}$ & 709,9 & abcd A & 392,1 bcd & 1402,3 & cde \\
\hline UFRGS 17 & 920,6 abcd $\mathrm{A}$ & 1007,3 & $\mathrm{ab} \mathrm{A}$ & $379,5 \mathrm{~cd}$ & 2817,1 & $\mathrm{a}$ \\
\hline UFRGS 14 & 904,3 abcd A & 813,6 & abcd A & $*$ & 1815,3 & abcde \\
\hline UFRGS 940772 & 859,6 abcd A & 1037,8 & a $\mathrm{A}$ & $329,0 \mathrm{~cd}$ & 1149,9 & de \\
\hline UFRGS 93641 & 853,7 abcd $\mathrm{A}$ & 712,5 & abcde B & $249,8 \mathrm{~cd}$ & 1736,9 & abcde \\
\hline UFRGS 952602 & 830,4 abcd $\mathrm{A}$ & 587,6 & abcde A & 477,6 abcd & 1006,0 & $\mathrm{e}$ \\
\hline UFRGS 910906 & 762,0 bcd $A$ & 315,2 & e $\mathrm{B}$ & $226,3 \mathrm{~d}$ & 1181,3 & de \\
\hline UFRGS 953167 & 662,4 cd $A$ & 483,2 & bcde A & 411,5 bcd & 975,9 & $\mathrm{e}$ \\
\hline UFRGS 960845-2 & 613,3 d A & 440,3 & cde A & 447,5 abcd & $*$ & \\
\hline C. V. $(\%)$ & & & & 35,59 & 27,1 & \\
\hline
\end{tabular}

Médias seguidas por letras distintas diferem entre si pelo teste de Tukey ao nível de 5\% de probabilidade.

Letras maiúsculas indicam comparação entre estádios.

Letras minúsculas indicam comparação entre genótipos.

* O genótipo não apresentou pústulas em número suficiente para a avaliação

Em 1999 o comprimento de pústulas variou de 368,8 a $545,5 \mu \mathrm{m}$, sendo as maiores pústulas observadas na cultivar UFRGS 14 (Tabela 3). Nas linhagens UFRGS 41698-22, UFRGS 42085-10 e UFRGS 950120 e na cultivar UFRGS 17 também se observou pústulas grandes. Dentre os genótipos com as menores pústulas estão UFRGS 910906, UFRGS 940263-3 e UFRGS 940772. A linhagem UFRGS 93641 teve as menores pústulas neste ano.

\section{Produção de esporos por pústula}

Houve diferença significativa entre os genótipos quanto à produção de esporos por pústula em folhas bandeira e bandeira-1coletadas no campo em ambos os anos, 1998 e 1999 ( $P>F=0,00005$ e 0,00001 , respectivamente).
Em 1998 verificou-se a produção de 160,4 a 906,7 esporos por pústula (Tabela 4). A maior esporulação foi observada na cultivar UFRGS 16, sendo que nas linhagens UFRGS 41699-3 e UFRGS 950120 também se observou alta esporulação. O menor número de esporos produzidos por pústulas foi observado nas linhagens UFRGS 910906 e UFRGS 921260.

Nas folhas coletadas no ano de 1999, a produção de esporos por pústula variou entre 908 e 2.817,1 sendo na cultivar UFRGS 17 a maior esporulação (Tabela 4). Ainda com alta esporulação, observou-se a cultivar UFRGS 16 e a linhagem UFRGS 41709-5. A menor produção de esporos foi observada nos genótipos UFRGS 952602, UFRGS 952576-1/2, UFRGS 953167, UFRGS 952403, UFRGS 953109 e UFRGS 960286-1 
Resistência quantitativa à ferrugem da folha em genótipos de aveia...

\section{DISCUSSÃO}

O progresso lento da moléstia observado no campo, que caracteriza a resistência quantitativa, é considerado a resultante dos efeitos combinados de componentes de resistência tais como baixa eficiência de infecção, período latente longo, pústulas pequenas, esporulação reduzida e período infeccioso curto. Assim como para a reação avaliada no campo (Chaves et al., 2004), há grande variabilidade entre os genótipos testados para todas estas características, com exceção do período de latência em plântulas, sendo que os componentes com maior variabilidade foram a eficiência de infecção e a produção de esporos por pústula. O comprimento de pústulas e o período de latência em plantas adultas apresentam variabilidade um pouco menor do que os outros componentes.

$\mathrm{Na}$ Tabela 5 estão resumidas as características dos genótipos estudados em relação aos componentes de resistência, avaliados em condições controladas. A caracterização está baseada nos testes de médias da análise estatística (Tabelas 1 a 4) e na comparação relativa entre os genótipos para cada componente de resistência. Os genótipos resistentes a campo apresentam uma combinação de componentes altamente favorável, com eficiência de infecção baixa a média, comprimento de pústulas pequeno a médio, esporulação baixa e período de latência em planta adulta longo a médio. Estas características provavelmente foram responsáveis pela grande redução na quantidade de doença observada no campo nestes genótipos em relação aos suscetíveis (mais de 88\% na linhagem UFRGS 960845-2, e mais de 55\% na linhagem UFRGS 910906, em relação à ASCPD da cultivar suscetível UFRGS 7) (Chaves, et al., 2004). Os genótipos dos demais grupos, apresentam variação quanto aos componentes de resistência, sendo que alguns deles apresentam características desejáveis. No entanto, a combinação de componentes verificada nos genótipos destes grupos parece estar relacionada com o que foi observado no campo.

A comparação entre o período de latência, esporulação e comprimento de pústulas, medidos em condições controladas nos dois estádios estudados, sugere que a expressão da resistência nesta interação patógeno-hospedeiro pode ser semelhante à resistência de planta adulta à ferrugem da folha em algumas cultivares de trigo (Triticum aestivum L.) (Roelfs, 1988; Ezzahiri \& Roelfs, 1989; Pretorius \& Roelfs, 1996; Barcellos et al., 2000), em que a resistência aumenta à medida que as plantas ficam mais velhas (Knott, 1988). Para o conjunto de genótipos testados, verifica-se que, em plantas adultas, o período de latência é significativamente mais longo e a esporulação é menor. Quanto ao comprimento de pústulas, verifica-se que o genótipo UFRGS 960845-2, caracterizado como resistente no campo, teve as menores pústulas em ambos os estádios, quando comparado aos demais genótipos, não havendo diferença entre o tamanho das lesões nos dois estádios avaliados. Na maioria (23) dos 30 genótipos em que existe diferença entre os estádios quanto ao tamanho das lesões, verifica-se que as pústulas em plantas adultas são menores do que as de plântulas; e, dos sete genótipos com as maiores pústulas em plantas adultas, cinco estão entre os genótipos caracterizados no campo como suscetíveis.

Os componentes de resistência medidos em folhas coletadas no campo tiveram, de maneira geral, comportamento inconsistente de um ano para outro, tanto em relação aos valores quanto à posição dos genótipos, a despeito da uniformidade das folhas, que foram coletadas no mesmo estádio de desenvolvimento da aveia. Uma observação inesperada proveniente deste tipo de avaliação, foi que a esporulação em 1998, quando a epidemia foi severa, apresentou valores muito inferiores àqueles observados em 1999. Uma hipótese para esta observação seria justamente a alta severidade observada em 1998. Neste ano a epidemia começou excepcionalmente mais cedo, ocasionando uma exposição das plantas à moléstia praticamente durante todo o seu ciclo. As folhas bandeira e bandeira- 1 coletadas neste ano, foram atingidas muito cedo e provavelmente no momento da coleta já estavam debilitadas, o que pode ter proporcionado uma esporulação pouco abundante nesta fase.

Pelos resultados obtidos neste trabalho, não há, aparentemente, um único componente responsável pela expressão da resistência quantitativa à ferrugem da folha da aveia no campo, o que difere do que foi relatado para este patossistema (Thomé et al., 1997; Brake \& Irwin, 1992) e para outras interações envolvendo ferrugens (Parlevliet \&Van Ommeren, 1975; Johnson \& Wilcoxson, 1979; Broers, 1997). A resistência parcial à ferrugem da folha da aveia parece comportar-se de modo semelhante à da ferrugem do feijoeiro (Phaseolus vulgaris L.) (Habtu \& Zadoks, 1995), a qual resulta da ação conjunta de vários componentes de resistência.

Os testes em condições controladas para avaliação dos componentes de resistência, confirmam a expressão da característica, diminuindo a possibilidade de que a resistência observada a campo seja reflexo da baixa freqüência de raças virulentas do patógeno. Ainda, a quantificação dos componentes de resistência possibilitará que os níveis de resistência parcial à ferrugem da folha da aveia possam ser progressivamente aumentados em um programa de melhoramento, à medida que componentes favoráveis possam ser identificados e acumulados em genótipos com características agronômicas superiores. Os componentes de resistência medidos em material coletados no campo não fornecem dados consistentes e, portanto, não devem ser considerados como indicadores da resistência quantitativa nesta interação patógeno-hospedeiro.

Os genótipos avaliados neste estudo com níveis satisfatórios de resistência quantitativa à ferrugem da folha da aveia, representados por aqueles pertencentes aos resistentes e moderadamente resistentes, podem ser utilizados em programas de melhoramento genético para transferência de suas características. Os genótipos dos outros grupos com componentes desejáveis, também poderão ser utilizados em cruzamentos, de forma a acumular mais componentes favoráveis, aumentando assim os níveis de resistência parcial expressa no campo em genótipos suscetíveis. 
M.S. Chaves et al.

TABELA 5 - Características de genótipos de aveia (Avena sativa) quanto à eficiência de infecção, período de latência, produção de esporos por pústula e comprimento de pústulas em condições controladas

\begin{tabular}{|c|c|c|c|c|c|c|c|c|c|c|c|c|}
\hline \multirow{3}{*}{$\begin{array}{l}\text { Genótipo e sua reação } \\
\text { no campo }\end{array}$} & \multicolumn{12}{|c|}{ Característica em condcỗes controladasi } \\
\hline & \multicolumn{4}{|c|}{ Plântula } & \multicolumn{8}{|c|}{ Planta adulta } \\
\hline & E. I & $\mathrm{x}<\mathrm{G} \cdot \mathrm{R}^{*}$ & C. P. & $\mathbf{x}<$ G.R.* & ESP. & $\mathbf{x}<$ G.R.* & P. L. & x>G.R.* & C.P. & $\mathbf{x}<\mathrm{G} . \mathbf{R}$.* & ESP. & $\mathbf{x}<\mathbf{G} \cdot \mathbf{R}^{*}$ \\
\hline \multicolumn{13}{|l|}{ Resistentes } \\
\hline UFRGS 910906 & média & $(2,8)$ & médio & $(0,86)$ & baixa & $(0,51)$ & longo & $(1,45)$ & pequeno & $(0,79)$ & baixa & $(0,30)$ \\
\hline UFRGS $960845-2$ & baixa & $(73,8)$ & pequeno & $(0,71)$ & baixa & $(0,41)$ & médio & $(1,36)$ & pequeno & $(0,76)$ & baixa & $(0,42)$ \\
\hline \multicolumn{13}{|c|}{ Moderadamente resistentes } \\
\hline UFRGS 41698-22 & média & $(3,6)$ & grande & G.R.** & alta & $(0,83)$ & médio & $(1,30)$ & médio & $(0,84)$ & alta & $(0,88)$ \\
\hline UFRGS $41709-5$ & -.- & & médio & $(0,87)$ & média & $(0,72)$ & médio & $(1,36)$ & pequeno & $(0,78)$ & média & $(0,81)$ \\
\hline UFRGS $42085-10$ & média & $(6,9)$ & médio & $(0,88)$ & média & $(0,73)$ & médio & $(1,22)$ & médio & $(0,81)$ & média & $(0,77)$ \\
\hline UFRGS $41721-21$ & alta & $(1,5)$ & médio & $(0,85)$ & alta & $(0,84)$ & médio & $(1,23)$ & médio & $(0,85)$ & média & $(0,62)$ \\
\hline UFRGS 953133 & baixa & $(21,1)$ & pequeno & $(0,68)$ & média & $(0,77)$ & longo & $(1,57)$ & pequeno & $(0,79)$ & média & $(0,63)$ \\
\hline UFRGS 16 & média & $(2,7)$ & médio & $(0,86)$ & média & $(0,63)$ & médio & $(1,40)$ & médio & $(0,81)$ & média & $(0,56)$ \\
\hline UFRGS 93641 & média & $(2,9)$ & médio & $(0,80)$ & média & $(0,58)$ & longo & $(1,42)$ & médio & $(0,83)$ & média & $(0,67)$ \\
\hline UFRGS 93576 & média & $(3,5)$ & médio & $(0,82)$ & alta & G.R.** & médio & $(1,38)$ & médio & $(0,82)$ & média & $(0,84)$ \\
\hline UFRGS 953304 & baixa & $(11,6)$ & grande & $(0,90)$ & média & $(0,65)$ & médio & $(1,37)$ & médio & $(0,82)$ & média & $(0,61)$ \\
\hline \multicolumn{13}{|c|}{ Moderadamente suscetiveis } \\
\hline UFRGS 940263-3 & baixa & $(30,3)$ & médio & $(0,85)$ & média & $(0,82)$ & longo & $(1,57)$ & médio & $(0,81)$ & média & $(0,49)$ \\
\hline UFRGS 94638-B & alta & $(1,4)$ & médio & $(0,84)$ & média & $(0,78)$ & médio & & medio & $(0,83)$ & média & $(0,50)$ \\
\hline UFRGS 940772 & $\begin{array}{c}\text { média/ } \\
\text { alta }\end{array}$ & $(2,4)$ & médio & $(0,86)$ & média & $(0,58)$ & curto & $(1,09)$ & grande & $(0,98)$ & alta & G.R.** \\
\hline UFRGS 953285 & média & $(3,7)$ & pequeno & $(0,79)$ & média & $(0,74)$ & médio & $(1,22)$ & médio & $(0,83)$ & baixa & $(0,44)$ \\
\hline CTC 3 & baixa & $(11,0)$ & médio & $(0,86)$ & média & $(0,62)$ & médio & $(1,33)$ & médio & $(0,87)$ & média & $(0,68)$ \\
\hline UFRGS 911748-1 & alta & $(1,7)$ & médio & $(0,85)$ & média & $(0,77)$ & médio & $(1,38)$ & médio & $(0,86)$ & alta & $(0,89)$ \\
\hline \multicolumn{13}{|l|}{ Suscetiveis } \\
\hline UFRGS 7 & alta & G. R.** & médio & $(0,86)$ & média & $(0,83)$ & curto & G.R.** & médio & $(0,87)$ & média & $(0,64)$ \\
\hline UFRGS 10 & média & $(5,27)$ & médio & $(0,87)$ & alta & $(0,91)$ & médio & $(1,15)$ & grande & G.R.** & média & $(0,55)$ \\
\hline UFRGS 14 & alta & $(2,3)$ & grande & $(0,89)$ & média & $(0,61)$ & curto & $(1,03)$ & médio & $(0,84)$ & média & $(0,78)$ \\
\hline UFRGS 17 & média & $(6,7)$ & médio & $(0,87)$ & média & $(0,62)$ & médio & $(1,20)$ & grande & $(0,90)$ & alta & $(0,97)$ \\
\hline UFRGS 41699-3 & $\begin{array}{l}\text { média/ } \\
\text { alta }\end{array}$ & $(2,5)$ & médio & $(0,82)$ & média & $(0,63)$ & curto & $(1,13)$ & médio & $(0,83)$ & média & $(0,55)$ \\
\hline UFRGS 953109 & $\begin{array}{c}\text { média/ } \\
\text { alta }\end{array}$ & $(1,6)$ & pequeno & $(0,78)$ & média & $(0,69)$ & médio & $(1,14)$ & médio & $(0,87)$ & média & $(0,69)$ \\
\hline UFRGS 952403 & baixa & $(8,8)$ & médio & $(0,84)$ & média & $(0,76)$ & médio & $(1,35)$ & pequeno & $(0,79)$ & média & $(0,76)$ \\
\hline UFRGS 952602 & média & $(3,2)$ & médio & $(0,84)$ & média & $(0,56)$ & médio & $(1,21)$ & pequeno & $(0,79)$ & média & $(0,57)$ \\
\hline UFRGS 922003 & média & $(3,8)$ & pequeno & $(0,75)$ & alta & $(0,84)$ & médio & $(1,34)$ & médio & $(0,83)$ & baixa & $(0,39)$ \\
\hline UFRGS 921260 & média & $(3,3)$ & médio & $(0,84)$ & média & $(0,68)$ & curto & $1,11)$ & médio & $(0,87)$ & média & $(0,50)$ \\
\hline UFRGS 950120 & $\begin{array}{l}\text { baixa/ } \\
\text { média }\end{array}$ & $(7,5)$ & médio & $(0,82)$ & média & $(0,75)$ & médio & $(1,29)$ & grande & $(0,96)$ & média & $(0,81)$ \\
\hline UFRGS 952576-1/2 & -.- & & médio & $(0,85)$ & media & $(0,66)$ & curto & $(1,13)$ & grande & $(0,90)$ & média & $(0,74)$ \\
\hline UFRGS 960286-1 & -.. & & médio & $(0,80)$ & média & $(0,64)$ & médio & $(1,28)$ & pequeno & $(0,78)$ & média & $(0,66)$ \\
\hline UFRGS 953167 & alta & $(1,9)$ & médio & $(0,82)$ & baixa & $(0,45)$ & médio & $(1,18)$ & grande & $(0,92)$ & média & $(0,47)$ \\
\hline
\end{tabular}

E. I. : Eficiência de Infecção; C. P.: Comprimento de pústulas; ESP.: Esporulação; P. L.: Período de latência

${ }^{*} \mathrm{x}<$ ou $\mathrm{x}>$ G.R.: $\mathrm{N}^{\circ}$ de vezes menor ou maior que o Genótipo de Referência

**G.R. (Genótipo de Referência): Genótipo com a condição extrema de suscetibilidade para cada característica (=1x): maior eficiência de infecção, maior pústula, maior esporulação e menor período de latência

\section{REFERÊNCIAS BIBLIOGRÁFICAS}

BARCELlOS, A.L., ROELFS, A.P. \& FERNANDES, M.I.B. Inheritance of adult plant leaf rust resistance in the Brazilian wheat cultivar Toropi. Plant Disease 84:90-93. 2000.

BRAKE, V.M. \& IRWIN, J.A.G. Partial resistance of oats to Puccinia coronata f. sp. Avenae. Australian Journal of Agricultural Research 43:1217-1227. 1992.

BROERS, L.H.M. Components of quantitative resistance to yellow rust in ten spring bread wheat cultivars and their realtions with fiels assessments. Euphytica 96:215-223. 1997.

CASTRO, L.A.S. \& COUTO, M.E.O. Herborização de órgãos vegetais em condições refrigeradas. Fitopatologia Brasileira 24:351. 1998.

CHAVES, M.S., MARTINELli, J.A. \& FEDERIZZI, L.C. Resistência quantitativa à ferrugem da folha em genótipos de aveia branca: I - Caracterização da reação em condições de campo. Fitopatologia Brasileira 28:039-046. 2004.

EZZAHIRI, B. \& ROELFS, A.P. Inheritance and expression of adult plant resistance to leaf rust in Era wheat. Plant Disease 73:549-551. 1989. 
Resistência quantitativa à ferrugem da folha em genótipos de aveia...

FEDERIZZI, L.C. \& STUTHMAN, D. Porque genes maiores para resistência à ferrugem da folha têm pouca durabilidade no Brasil. Resumos. $18^{\text {a }}$ Reunião da Comissão Brasileira de Pesquisa de Aveia, Londrina, PR. 1998, pp.1-2.

HEAGLE, A.S. \& MOORE, M.B. Some effects of moderate adult resistance to crown rust of oats. Phytopathology 60:461-466. 1970.

HABTU, A. \& ZADOKS, J.C. Components of partial resistance in Phaseolus beans against an Ethiopian isolate of bean rust. Euphytica 83:95-102. 1995.

JOHNSON, R.A critical analysis of durable resistance. Annual Review of Phytopathology 22:309-330. 1984.

JOHNSON, R. \& WILCOXSON, R.D. Inheritance of slow rusting of barley infected with Puccinia hordei and selection of latent period and number of uredia. Phytopathology 69:145-151. 1979.

KNOTT, D.R. Using polygenic resistance to breed for stem rust resistance in wheat. In: Simmonds, N.W. \& Rajaram, S. (Eds.) Breeding Strategies for Resistance to the Rusts Of Wheat. Mexico. CIMMYT. 1988. pp.39-47.

LEONARD, K.J. O que sabemos sobre a ferrugem da folha em aveia? Palestra proferida durante a XIX Reunião da Comissão Brasileira de Pesquisa de Aveia, realizada de 30 de março a 1 de abril de 1999, Porto Alegre, RS.

MARTIN, C.D., MILLER, J.D.\& BUSH, R.H. Quantitation of slow rusting in seedling and adult spring wheat. Canadian Journal of Botany 57:1550-1556. 1979.

MARTINELLI, J.A. Induced resistance of barley (Hordeum vulgare L.) to powdery mildew (Erisiphe graminis f. sp. hordei Em. Marchal) and its potential for crop protection. (Tese de doutorado). Cambridge. Cambridge University. 1990.

MARTINELLI, J.A., CHAVES, M.S., FEDERIZZI, L.C., MILACH, S.C.K. \& ALMEIDA, J.L. Análise da virulência de alguns isolados de Puccinia coronata avenae no sul do Brasil. Resumos. Reunião da Comissão Brasileira de Pesquisa de Aveia, Londrina, PR. 1998, pp.1719.

OHM, J.W. \& SHANER, G.E. Three components of slow leaf-rusting at different growth stages in wheat. Phytopathology 66:1356-1360. 1976.

PARLEVLIET, J. E. Partial resistance of barley to leaf rust, Puccinia hordei. III. The inheritance of the host plant effect on latent period in four cultivars. Euphytica 25:241- 248. 1976.

PARLEVLIET, J.E. Components of resistance that reduce the rate of epidemic development. Annual Review of Phytopathology 17:203222. 1979.

PARLEVLIET, J.E. Resistance of the nonrace-specific type. In: Bushnell, W.R. \& Roelfs, A.P. (Eds.) The Cereal Rusts: Diseases, Distribution, Epidemiology and Control. New York. Academic Press. 1985. pp.501-525.

PARLEVLIET, J.E. Identification and evaluation of quantitative resistance. In: Leonard, K.J. \& Fry, W.E. (Eds.) Plant Disease Epidemiology. Dordrecht. Kluwer Academic Publishers. 1989. pp.215248.

PARLEVLIET, J.E. \& VAN OMMEREN, A. Partial resistance of barley to leaf rust, Puccinia hordei. II- Relationship between field trials, micro plot tests and latent period Euphytica 24:293-303. 1975.

PRETORIUS, Z.A. \& Roelfs, A.P. The role of Lr 10, Lr 13 and Lr 34 in the expression of adult plant resistance to leaf rust in wheat cultivar Era. Plant Disease 80:199-202. 1996.

ROELFS, A.P. Resistance to leaf and stem rusts in wheat. In: Simmonds, N.W. \& Rajaram, S. (Eds.) Breeding Strategies for Resistance to the Rusts of Wheat. Mexico. CIMMYT. 1988. pp.1022.

SZTEJNBERG, A. \& WAHL, I. Mechanisms and stability of slow stem rusting resistance in Avena sterilis. Phytopathology 66:74-80. 1976.

THOMÉ, G.C.H., MILACH, S.C.K. \& VOLK, L.B. da S. \& FEDERIZZI, L.C. Tamanho de pústula: um componente importante da resistência parcial à ferrugem da folha em aveia. Summa Phytopathologica 23:262-264. 1997.

WAHL, I., WILCOXSON, R.D.R. \& OWELL, J.B. Slow rusting of wheat with stem rust detected in the glasshouse. Plant Disease 64:5456. 1980.

WILCOXSON, R.D. Genetics of slow rusting in cereals. Phytopathology 71:989-992. 1981.

ZIMMER, D.E., SCHAFER, J.F. \& PATTERSON, F.L. Mutations for virulence in Puccinia coronata. Phytopathology 53:171-176. 1963.

ZONTA, E.P. \& MACHADO, A. SANEST. Sistema de Análise Estatística para Microcomputadores. Pelotas. Universidade Federal de Pelotas. 1984. 